\title{
Correction to: The state of HRM in the Middle East: Challenges and future research agenda
}

\author{
Pawan Budhwar $^{1}$ - Vijay Pereira ${ }^{2,3}$. \\ Kamel Mellahi ${ }^{4} \cdot$ Sanjay Kumar Singh ${ }^{5}$
}

Published online: 25 July 2018

C Springer Science+Business Media, LLC, part of Springer Nature 2018

\section{Correction to: Asia Pac J Manag \\ https://doi.org/10.1007/s10490-018-9587-7}

The author group in the original version of this article contained a mistake. The last author's name should be Sanjay Kumar Singh, instead of Sanjay Singh. The correct name appears above.

The original article has been corrected.

The online version of the original article can be found at https://doi.org/10.1007/s10490-018-9587-7

Vijay Pereira

vijay.pereira@port.ac.uk

1 Aston Business School, Birmingham, UK

2 Wollongong Business School, Dubai, UAE

3 University of Portsmouth, Richmond Building, Portland St., Portsmouth PO1 3DE, UK

4 Warwick Business School, Coventry, UK

5 Abu Dhabi University, Abu Dhabi, UAE 